Geopolítica(s) Revista de estudios sobre espacio y poder ISSN: 2172-3958

\title{
La Ciudad Transnacional. Claves para entender la ciudad contemporánea
}

Federico Besserer y Raúl Nieto (eds.) (2013) La ciudad trasnacional comparada: modos de vida, gubernamentalidad y desposesión (Colección Estudios Transnacionales). México: Universidad Autónoma Metropolitana - Unidad Iztapalapa/ Juan Pablos Editor. 441 pp. ISBN 978-607-28-0358-9.

¿Cómo comprender las llamadas ciudades globales sin la mano de obra migrante que ha edificado sus calles y edificios; el desarrollo de sectores inmobiliarios en las poblaciones de origen de dichos migrantes, sin valorar las remesas que ellos envían; el funcionamiento de los modos de producción contemporáneos, sin percibir las nuevas formas de trabajo y vivienda de comunidades migrantes; la complejidad de los “barrios de inmigrantes”, sin analizar las prácticas cotidianas de habitarlos y las relaciones que tejen cotidianidades telemática en lugares discontinuos?

A este tipo de preguntas se enfrentan Federico Besserer y Raúl Nieto, del Departamento de Antropología de la Universidad Autónoma Metropolitana-Unidad Iztapalapa en México, quienes editan este volumen. Sugieren buscar caminos para entender la particularidad de los modos de vida que articulan periferias urbanas globales con redes transnacionales de migrantes, en el marco de lógicas políticas, sociales, económicas y culturales que estructuran nuevas geografías urbanas no marcadas por una continuidad territorial, sino por la configuración de espacialidades sociales transnacionales que tejen de forma novedosa las expresiones físicas y prácticas de las ciudades.

Esta perspectiva de comprender la Ciudad Transnacional, propuesta inicialmente por Besserer y Oliver ${ }^{1}$, es explorada en esta obra compilatoria desde tres diferentes tipologías: la Ciudad Fronteriza, la Ciudad Diaspórica y la Ciudad Clusterizada; las cuales, organizadas como partes, se corresponden con los diferentes capítulos que componen este libro.

La primera tipología reúne “zonas metropolitanas que no están acotadas por las fronteras nacionales, sino divididas por ellas,” (p. 25), cuyos habitantes desarrollan formas de vida "interdomésticas” no constreñidas por las geografías nacionales (p. 25). Dicha tipología, es trabajada por Areli Veloz, Lizet Jiménez y Loreina Urbalejo, quienes desde la frontera entre Estados Unidos y México muestran la importancia de la construcción de las diferencias históricas, políticas, legales, éticas e identi-

$1 \quad$ Federico Besserer y Daniela Oliver (eds) Ensamblando la ciudad transnacional. México, Universidad Autónoma Metropolitana-Unidad Iztapalapa / Juan Pablos Editor, 2014. 
tarias, que marca la frontera política y que inciden en las prácticas de habitar las ciudades fronterizas.

Sus trabajos cuestionan la idea popularizada sobre la artificialidad, inoperatividad e inclusive la inexistencia de la frontera. Justamente sugieren que es la particularidad de las negociaciones locales de lo fronterizo, lo que permite el desarrollo de formas de habitar que pueden atravesarla, sin que eso indique que se rompan las diferencias construidas en relación a ella.

A pesar de los interesantes e innovadores análisis propuestos, particularmente en el trabajo de Veloz sobre las construcciones políticas del sexo y el placer en el marco de las prácticas del aborto, considero que esta tipología no es explorada de forma cabal. No se llegan a analizar de forma clara los espacios sociales y la materialidad de éstos en las ciudades, pese a que Urbalejo realice algunos esfuerzos en este sentido. En general se habla poco de la Ciudad Fronteriza como tal, restringiendo el análisis a los efectos de la frontera en determinadas prácticas sociales, quedando desdibujada la particularidad de lo urbano y su articulación con lo fronterizo.

El segundo tipo, la Ciudad Diaspórica, es resultado de complejos procesos conformadores de espacios sociales que articulan comunidades con modos de vida transnacionales, profundamente vinculados y localizados en los márgenes urbanos de ciudades centrales y periféricas, “ensamblados” por dichas comunidades en “territorios discontinuos" (p. 27).

Este tipo nos ofrece muy buenas posibilidades de análisis, al romper la "continuidad geográfica” desde donde tradicionalmente se comprende lo urbano, permitiendo articular nuevas configuraciones que retan incluso las soberanías de los Estados nacionales, que constriñen gran parte del análisis del primer tipo expuesto.

Los trabajos de Mónica Cinco y Ximena Alba sobre la diáspora y los circuitos migratorios chinos, localizados en Ciudad de México (Cinco), Mexicali y Paris (Alba), el de Adriana Solís sobre los mixtecos en las ciudades mexicanas y estadounidenses, así como el de Nancy Wence sobre las redes transnacionales construidas entre Cochabamba y Madrid, muestran diferentes facetas de esas configuraciones de la Ciudad Diaspórica. Resaltan las diversas formas en que las ciudades son construidas y apropiadas por las comunidades migrantes, mientras se construye una discontinuidad del espacio urbano transnacional marcado por pautas de vida, relaciones, movilidades y estrategias de comunicación. Así mismo indican que estas ciudades, a pesar de su separación física, enlazan lugares que configuran enclaves económicos, sociales y culturales que retan las formas clásicas de comprender las dinámicas urbanas en el marco de los procesos globales contemporáneos.

La tercera clase, la Ciudad Clusterizada, es entendida como una porción de la ciudad donde se emplazan procesos desconcentrados de producción, asociados a capitales transnacionales que buscan en clusters las mejores condiciones de rentabilidad "minimizando costos" — entre ellos de mano de obra - y donde confluyen trabajadores muchas veces vinculados a formas de vida transnacionales (p. 28).

Estos elementos son presentados y analizados de forma detallada en los cuatro trabajos que discuten diversas perspectivas de la particularidad de estos clusters en sectores terciarios de la economía. Dos de ellos se centran en empresas de call centers (Maribel Romero en Tijuana y Luis Meoño en Guatemala) y su articulación con circuitos migratorios. Valentina Glockner estudia la relación de los parques tecnológicos en Bangalor con la proliferación de slums en dicha ciudad. Y Daniela 
Oliver analiza los clusters turísticos en Baja California que producen un "simulacro de la fantasía” (p. 370) mientras esconden "tras bambalinas" los trabajadores de dicha industria.

En términos generales, el gran aporte de esta categoría es comprender la terciarización de las formas de producción, su localización y búsqueda de fuerza laboral de forma articulada con circuitos migratorios inéditos. Lo anterior sugiere, por una parte, una diversificación de la mano de obra vinculada formal e informalmente a nuevas economías urbanas transnacionales, así como estructuras sociales y espaciales de exclusión que magnifican la segregación urbana en este tipo de ciudades.

La obra en general ofrece puntos de vista interesantes para comprender la articulación entre los procesos transnacionales del capital y los circuitos globales de migración. Ambos procesos contribuyen a la construcción de las ciudades contemporáneas. Quizá el mayor aporte lo constituye el debate teórico y metodológico para comprender la Ciudad Diaspórica, ya que logra romper con acercamientos más clásicos sobre los efectos de la migración en las ciudades, permitiendo entenderlas en el marco de circuitos globales y espacialidades sociales transnacionales.

El tipo de Ciudad Clusterizada también ofrece algunos elementos innovadores que recuperan discusiones recientes en la geografía, la sociología y la antropología urbanas, que han trascendido los estudios sobre maquiladoras. Sin embargo, su mayor aporte considero que consiste en evidenciar los vínculos entre circuitos migratorios diversos, procesos de reconfiguración global de los modos de producción y la creciente segregación socioespacial.

Por último, el tipo de Ciudad Fronteriza, pese a los esfuerzos analíticos de las autoras de dicho apartado, no alcanza a satisfacer las pretensiones de vincular los órdenes fronterizos modernos de los Estados nacionales con las nuevas lógicas de organización global de la economía y la mano de obra. Quizá el abuso del "laboratorio norteamericano" para entender la Ciudad Fronteriza, o la pretensión inmanente en la propuesta de trascender las geografías que marca la soberanía nacional, dificultan la comprensión de la articulación de éstos con las nuevas geografías discontinuas que los editores logran teorizar y ejemplificar mucho mejor en los otros tipos de ciudad. Es posible que la pretensión de "superar la frontera" los haya hecho caer en su trampa, al suponer su irrelevancia sin valorar plenamente su función en los más clásicos sentidos modernos, y el papel que tiene tanto en la vida cotidiana de quienes habitan poblaciones relacionadas con ella, como en la configuración de las lógicas planetarias contemporáneas. Justamente, las fronteras hoy en día cuestionan la aparente homogeneidad de un mundo global.

Pese a lo anterior, la Ciudad Transnacional Comparada es un excelente libro que articula varios debates y ofrece perspectivas innovadoras de gran pertinencia para comprender las dinámicas urbanas contemporáneas y su articulación transnacional.

Jorge Aponte Motta

Grupo de Estudios Transfronterizos,

Universidad Nacional de Colombia, Sede Amazonia Departamento de Geografía, Universidad Autónoma de Madrid Email: jmapontem@unal.edu.co 